\title{
Research on the Countermeasures to Improve the Audit Teaching Level in the Information Environment
}

Qiong Liu

Tongling University, Tongling 244000, Anhui, China

Research on the Training of Auditing Talents Based on the Blockchain Environment

\begin{abstract}
The audit course is a comprehensive subject with a certain degree of professional technical difficulty, and taking into account both theoretical and practical aspects. Students not only need to know the knowledge of auditing, but also understand the corresponding laws and regulations, and train themselves to have certain problem induction and Skills of analyze. This article studies the improvement of audit teaching level in the information environment, analyzes the problems in the current audit teaching, and proposes some teaching improvement measures, hoping to provide some useful suggestions to the majority of audit teachers in the teaching process.
\end{abstract}

Keywords: Information Environment; Audit Teaching; Improvement of Teaching Level; Countermeasure Research

With the advent of the information age, the social economy is developing at a speed beyond human imagination. In higher education teaching, more emphasis is placed on the cultivation of students' innovative and practical abilities, as far as auditing is a comprehensive discipline. How to train high-level innovative auditing talents has become a key concern of the majority of auditing teachers. Based on many years of auditing teaching experience and actual teaching conditions, the author proposes a series of teaching reform measures in response to the current problems in education and teaching, aiming to better enhance students' interest in learning and cultivate high-quality audit talents.

\section{Overview of audit teaching status in the information environment}

\subsection{The informatization concept of audit teachers is not strong}

At present, audit teachers in many universities have not recognized the major changes brought about by information technology to teaching, nor have they enhanced their own concept of informatization. The overall teaching methods and teaching concepts are still maintained in the original exam-oriented education concepts. There is a lack of understanding of advanced teaching concepts, the level of classroom teaching of auditing cannot be improved, and the classroom teaching atmosphere is slightly rigid, which makes it difficult to stimulate students' enthusiasm for learning.

\subsection{The lack of audit education information resources}

The teaching content of auditing has a strong conception. In order to complete the teaching task, the teacher basically revolves around the teaching textbook in the teaching process, and rarely expands the textbook content, and the overall teaching resources are slightly scarce. In addition, in the information environment, because the audit teaching content is more professional, the quality of many teaching resources is not very high, and the content and topic selection are relatively single, which makes it difficult to achieve effective interaction between teachers and students. Therefore, audit education information resources The lack of audit information has become an important factor affecting the development of audit information education.

\subsection{Lack of effective communication and interaction between teachers and between teachers and students}

Copyright @ 2020 Qiong Liu

doi: 10.18282/le.v9i7.1503

This is an open-access article distributed under the terms of the Creative Commons Attribution Non-Commercial License

(http://creativecommons.org/licenses/by-nc/4.0/), which permits unrestricted non-commercial use, distribution, and reproduction in any medium, provided the original work is properly cited. 
Nowadays, various universities are exploring and trying on the road of education informatization, and they are basically carried out in their own schools. This makes it difficult for audit education information resources to circulate among the major universities, and it is difficult for teachers to have opportunities Communication has caused a serious waste of audit education information resources. In addition, the educational concept has not been fundamentally updated. Many teachers only conduct so-called "information education" one-sidedly. There is still no effective communication between teachers and students, and the convenience of information technology has not been used to develop effective online, Offline communication, the actual teaching effect of audit teaching is still difficult to improve.

\section{Effective strategies for improving audit teaching level in information environment}

\subsection{Improve teachers' audit teaching level and strengthen teachers' informatization concept}

The teaching reform of auditing informatization is not only an application process of information technology, but also a teaching reform of advanced teaching concepts. First of all, we should insist on taking students as the center of teaching, change the traditional teaching methods around teachers, build a good classroom teaching environment, and improve students' classroom participation. Secondly, establish an information teaching model that focuses on learning and pays equal attention to learning and teaching, attaches importance to the role of information technology in actual teaching, and truly allows information technology to be fed back into actual teaching to enhance students' learning enthusiasm. Finally, teachers should continue to learn information technology and improve their theoretical knowledge and technical level through continuing education, so as to better keep up with the pace of the times.

\subsection{Create a good information teaching environment}

First of all, establish complete information teaching hardware facilities. Major colleges and universities should increase their investment in information technology equipment, so that every audit teacher can have access to the best information technology resources, and provide students and teachers with material guarantee for information technology teaching. Secondly, increase the informatization teaching training for teachers in software. Hire high-level educational technology experts to hold lectures on informatization teaching in the school, so that teachers can further understand the frontier development of informatization teaching theory in universities, and encourage teachers to establish good informatization teaching concepts. Finally, establish a complete education review system, implement a full range of educational evaluations on teaching methods and teaching effects, in order to supervise the effective implementation of information-based teaching reforms, build a complete information-based teaching environment, and improve students' learning efficiency.

\subsection{Integrate information teaching resources and improve the teaching level of audit teachers}

After mastering specific information technology, the teacher's teaching ability will be greatly improved. Teachers are not limited to simple demonstration teaching using multimedia means. A variety of emerging teaching methods can be developed and developed in actual teaching. Application, continuous integration of information teaching resources, perfect integration of information technology and auditing teaching, and improving the effectiveness of auditing teaching. For example, driving can use online teaching to realize online Q\&A, which perfectly eliminates the limitations of traditional teaching time and space, and makes learning and teaching more free; teachers can also record micro-class teaching videos and use refined language to focus on teaching, Difficulties are described in detail to enhance students' interest in learning; an auditing discussion area is set up in school forums, allowing students to speak freely, organizing various difficult questions and answers and question discussions, which greatly enhances the communication between teachers and students and students To build a better learning environment; use the network information system to track students' academic performance and learning conditions, including specific attendance, completion of daily homework, actual case discussion results, and final exam results And so on, teachers use this information to make comprehensive assessments to accurately understand the real learning situation of each student, so as to better carry out targeted teaching and comprehensively improve the comprehensive ability of students. 
In the informationized environment, there are higher requirements for auditing teaching. Teachers should change the traditional teaching concepts, combine the actual teaching situation, establish correct informationized teaching concepts, build a good informationized learning atmosphere, and effectively integrate various information resources, Truly take students as the main body of teaching, comprehensively improve the teaching level of auditing, and meet the new challenges brought by the new era of information education with better information network teaching.

\section{References}

1. Du Juling. Research on the Countermeasures to Improve the Audit Teaching Level in the Information Environment [J]. Friends of Accounting, 2008(34): 101-102.

2. Li Yansong, Wang Chungang. Research on the New Risks and Countermeasures of Internal Audit in the Information Environment [J]. Northern Economy and Trade, 2014, 000(009): 138-139.

3. Wang Qijie. Discussion on internal audit problems and countermeasures based on the information environment[J]. China Management Information Technology, 2008(13):55-58. 